\title{
Rutin alleviates cardiomyocyte injury induced by high glucose through inhibiting apoptosis and endoplasmic reticulum stress
}

\author{
JING WANG, RU WANG, JIALI LI and ZHUHUA YAO \\ Department of Cardiology, Tianjin Union Medical Center, Tianjin 300121, P.R. China
}

Received October 23, 2020; Accepted March 18, 2021

DOI: $10.3892 / \mathrm{etm} .2021 .10376$

\begin{abstract}
Diabetic cardiomyopathy is a common complication of diabetes, in which endoplasmic reticulum stress (ERS) serves an important role. Rutin can treat the myocardial dysfunction of diabetic rats. However, to the best of our knowledge, studies on the effects of Rutin on myocardial injury caused by diabetes from the perspective of ERS have not previously been reported. In the present study, the role of rutin in the regulation of ERS in myocardial injury was assessed. Different high glucose concentrations were used to treat $\mathrm{H} 9 \mathrm{C} 2$ myoblast cells to establish a myocardial damage model. A cell counting kit-8 assay was used to determine cell viability. A lactate dehydrogenase kit was used to detect cytotoxicity. Apoptosis levels were determined using a TUNEL assay. Western blotting was used to determine the expression levels of apoptosis-related proteins and ERS-related proteins, including heat shock protein A family member 5 , inositol-requiring enzyme- $1 \alpha, \mathrm{X}$-box binding protein 1 , activating transcription factor $6, \mathrm{C} / \mathrm{EBP}$-homologous protein (CHOP), cleaved caspase-12 and caspase-12. The anti-apoptotic and anti-ERS effects of Rutin on H9C2 cardiac cells induced by high glucose were examined after the administration of the ERS activator thapsigargin (TG). The results indicated that rutin could dose-dependently inhibit the level of apoptosis and ERS induced by high glucose in $\mathrm{H} 9 \mathrm{C} 2$ cells. After administration of the ERS activator TG, it was demonstrated that TG could reverse the anti-apoptotic and anti-ERS effects of rutin on H9C2 cells stimulated with high glucose. Collectively, the present results suggested that rutin may alleviate cardiomyocyte model cell injury induced by high glucose through the inhibition of apoptosis and ERS.
\end{abstract}

Correspondence to: Dr Zhuhua Yao, Department of Cardiology, Tianjin Union Medical Center, 190 Jieyuan Road, Hongqiao, Tianjin 300121, P.R. China

E-mail: zhuhua5969@163.com

Key words: rutin, diabetic cardiomyopathy, cardiomyocyte injury, endoplasmic reticulum stress, apoptosis

\section{Introduction}

Diabetic cardiomyopathy is a common complication of diabetes. Due to metabolic disorders and microvascular lesions, diabetic cardiomyopathy leads to extensive focal myocardial necrosis and subclinical cardiac dysfunction, which eventually develops into heart failure, arrhythmia, cardiac shock and even sudden death in severe cases (1-3)

Rutin is a flavonoid compound extracted from plants, and has been reported to exert antioxidant, anti-inflammatory, anti-allergic and anti-viral effects $(4,5)$. Rutin is thought to act on multiple tissues and organs in the body. For example, rutin has been demonstrated to protect gastric mucosal cells from damage (6) and has been suggested to promote the growth and proliferation of osteoblasts and inhibit osteoporosis (7). Rutin may also regulate the development of rat immune organs, including the chest, kidney and spleen (8). Traditional Chinese medicine rutin is thought to target a variety of signaling pathways to regulate tissues and organs (9). Previous studies have indicated that rutin can alleviate myocardial dysfunction in diabetic rats $(10,11)$. Rutin also has a protective effect on cobalt chloride-induced hypoxia injury of myocardial cells (12). Moreover, rutin inhibits apoptosis induced by myocardial ischemia reperfusion and protects $\mathrm{H} 9 \mathrm{C} 2$ cells from hydrogen peroxide-mediated damage via ERK1/2 and PI3K/AKT signaling (13).

Endoplasmic reticulum stress (ERS) is a cellular process induced by a variety of severe stress conditions, including hypoxia, ischemia, heat shock, gene mutation and oxidative stress $(14,15)$. ERS affects the folding of proteins in the endoplasmic reticulum and leads to the activation of the unfolded protein response (UPR) (16). The UPR mediates ERS and serves a role in activation of three major signaling pathways, including PERK, insulin response element 1 (IRE1) and activating transcription factor 6 (ATF6) (17-19). ERS-mediated apoptosis is associated with the IRE1 $\alpha$-mediated C-Jun $\mathrm{N}$-terminal kinase cascade and the PERK-dependent induction of the pro-apoptotic transcription factor C/EBP-homologous protein (CHOP) pathway (20-22). Therefore, it was hypothesized that prolonged or excessive ERS may lead to apoptosis, and a decrease in the level of ERS-induced apoptosis may alleviate diabetic cardiomyopathy. In addition, rutin has been reported to exert a protective effect against lipopolysaccharide-induced mastitis by inhibiting the activation of the nuclear factor- $\kappa \mathrm{B}$ signaling pathway and reducing ERS (23). However, 
to the best of our knowledge, studies on the effects of rutin on hyperglycemia-induced myocardial model cell injury from the perspective of ERS have not been reported.

The present study induced myocardial model cell damage at the cellular level, determined the effect of rutin on myocardial cell damage and discussed its underlying mechanism. The present study offers a strong theoretical basis for the use of rutin in the treatment of diabetic cardiomyopathy.

\section{Materials and methods}

Cell culture. H9C2 myoblast cells, a model of cardiomyocytes, were purchased from The Cell Bank of Type Culture Collection of The Chinese Academy of Sciences and were cultured in DMEM supplemented with 10\% FBS (Gibco; Thermo Fisher Scientific, Inc.). The cells were cultured in a humidified $37^{\circ} \mathrm{C}$ incubator with $5 \% \mathrm{CO}_{2}$. In the present study, the normal glucose group ( $5 \mathrm{mM}$ glucose; $\mathrm{NG}$ group) was set as a control group, while the mannitol group (MA; $45 \mu \mathrm{M}$ for $24 \mathrm{~h}$; Sigma-Aldrich; Merck KGaA) was established to exclude the osmotic pressure effects of high glucose (HG) on cells. H9C2 cells were incubated in complete medium containing $35 \mathrm{mM}$ glucose (final concentration in the medium) for $24 \mathrm{~h}$ at $37^{\circ} \mathrm{C}$, which was referred to as the $\mathrm{HG}$ group (24). H9C2 cardiac cells were administered rutin (cat. no. 19362115; Sigma-Aldrich; Merck KGaA) at final concentrations of 2, 10 and $50 \mu \mathrm{M}$ for $24 \mathrm{~h}$ at $37^{\circ} \mathrm{C}$ (13). Additionally, H9C2 cells were treated with $2 \mu \mathrm{M}$ ERS activator thapsigargin (TG; cat. no. T7459; Thermo Fisher Scientific, Inc.) for $4 \mathrm{~h}$.

Cell Counting Kit (CCK)-8. The viability of H9C2 cells was assessed using a CCK-8 assay (Beyotime Institute of Biotechnology) according to the manufacturer's instructions. Cells were seeded $\left(1 \times 10^{3}\right.$ cells/well) into 96 -well plates and were treated with rutin before $10 \mu \mathrm{l}$ of CCK- 8 solution was added to each well and the plates incubated for $4 \mathrm{~h}$ at $37^{\circ} \mathrm{C}$. The absorbance was recorded at $450 \mathrm{~nm}$ using a microplate reader.

Measurement of serum lactate dehydrogenase (LDH). A Cytotox 96 nonradioactive cytotoxicity assay kit (cat. no. G1780; Promega Corporation) was used according to the manufacturer's instructions. Cells were seeded $\left(1 \times 10^{3}\right.$ cells/well) into 96-well plates and treated with Rutin. Then, $10 \mu \mathrm{l}$ cell supernatant was mixed with $100 \mu \mathrm{LDH}$ reaction reagent at room temperature for $30 \mathrm{~min}$. The absorbance was determined using an enzyme-linked immunosorbent assay reader (Victor X3; PerkinElmer, Inc.) with a $490 \mathrm{~nm}$ filter.

TUNEL assay. Cell apoptosis was analyzed using a Click-iT ${ }^{\circledR}$ TUNEL Alexa Fluor ${ }^{\circledR}$ Imaging assay (cat. no. C10245; Invitrogen; Thermo Fisher Scientific, Inc.) according to the manufacturer's instructions. Cells were seeded $\left(1 \times 10^{6}\right.$ cells/well) into 6 -well plates and treated with rutin. Then, cells were collected and washed three times with PBS. Following fixation with $4 \%$ paraformaldehyde at room temperature for $20 \mathrm{~min}$, the cells were washed twice with PBS and $0.2 \%$ Triton-X-100 was added to the cells at room temperature for $5 \mathrm{~min}$. Subsequently, $50 \mu \mathrm{l}$ TUNEL assay solution (Boehringer Mannheim) was added to the cells and incubated

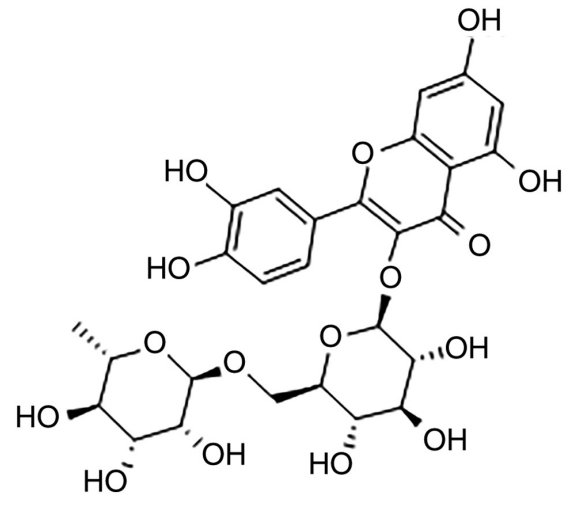

Figure 1. Chemical structure of rutin.

at $37^{\circ} \mathrm{C}$ in the dark for $60 \mathrm{~min}$. The detection solution was discarded and cells were washed three times with PBS. Images of the FITC-labeled TUNEL-positive cells were captured using an Olympus IX70 inverted microscope (magnification, x200; Olympus Corporation) according to the manufacturer's instructions. Cells were stained with DAPI (Thermo Fisher Scientific, Inc.) at room temperature for 15 mins.

Western blotting. Cells were seeded $\left(1 \times 10^{6}\right.$ cells/well) into 6-well plates and treated with Rutin. The H9C2 cells were collected and lysed with RIPA lysis buffer (Beyotime Institute of Biotechnology) for $30 \mathrm{~min}$ on ice. Subsequently, protein concentration was determined using a BCA protein assay kit (Bio-Rad Laboratories, Inc.). A total of $40 \mu \mathrm{g}$ protein was loaded onto each lane of $10 \%$ SDS-polyacrylamide gels to separate various proteins, which were subsequently transferred onto PVDF membranes. The membranes were blocked with $10 \%$ skimmed milk for $2 \mathrm{~h}$ at room temperature, followed by incubation with primary antibodies overnight at $4^{\circ} \mathrm{C}$. Subsequently, the membranes were incubated with goat anti-rabbit horseradish peroxidase-conjugated IgG secondary antibodies (1:5,000; cat. no. AA24142, Abcam) at room temperature for $1 \mathrm{~h}$. The signals were detected using an enhanced chemiluminescence reagent (Cytiva) and ImageJ software (version 146; National Institutes of Health) was used to analyze the fold changes of protein expression levels. The primary antibodies anti-Bax (1:1,000; cat. no. 14796S), anti-caspase-3 (1:1,000; cat. no. 9953S), anti-cleaved caspase-3 (1:1,000; cat. no. 9953S), anti-Bcl-2 (1:1,000; cat. no. 15071S), anti-HSPA5 (1:1,000; cat. no. 3183S), anti-IRE1 $\alpha$ (1:1,000; cat. no. 3294T), anti-X-box binding protein 1 (XBP1; 1:1,000; cat. no. $12782 \mathrm{~S})$, anti-ATF6 (1:1,000; cat. no. 65880T) anti-CHOP (1:1,000; cat. no. 2895T) and anti-GAPDH (1:1,000; cat. no. $5174 \mathrm{~S})$ were obtained from Cell Signaling Technology, Inc. In addition, anti-cleaved caspase-12 (1:1,000; cat. no. ab62484) and anti-caspase-12 (1:1,000; cat. no. ab8177) antibodies were obtained from Abcam.

Statistical analysis. Data are presented as the mean \pm SD $(\mathrm{n} \geq 3)$. Statistical analyses were performed using SPSS statistical software (version 22.0; IBM Corp.). Differences between multiple groups were assessed using a one-way ANOVA followed by Tukey's post hoc test. $\mathrm{P}<0.05$ was considered to indicate a statistically significant difference. 

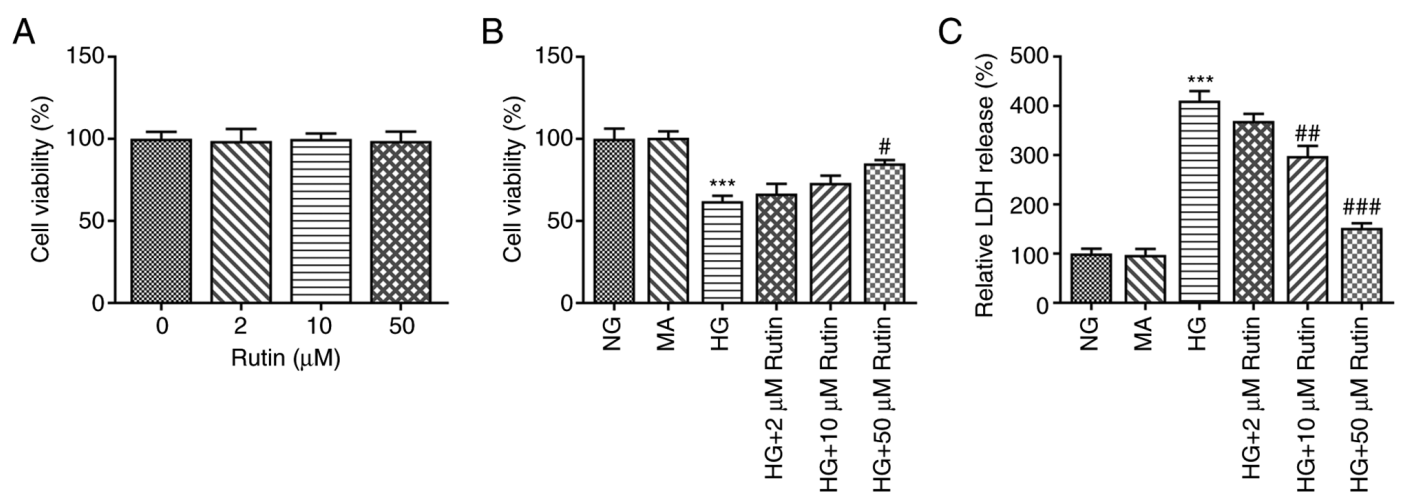

Figure 2. Rutin inhibits cell viability and increases cytotoxicity in H9C2 cells incubated in HG. (A) Cell viability was determined by CCK-8 after rutin treatment. (B) Cell viability was determined by CCK-8 after HG and rutin treatment. (C) The LDH kit was used to determine the level of cytotoxicity. HG, high glucose;

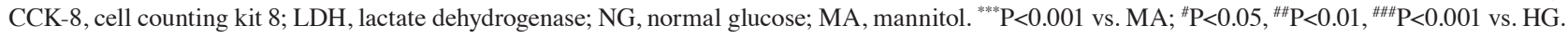
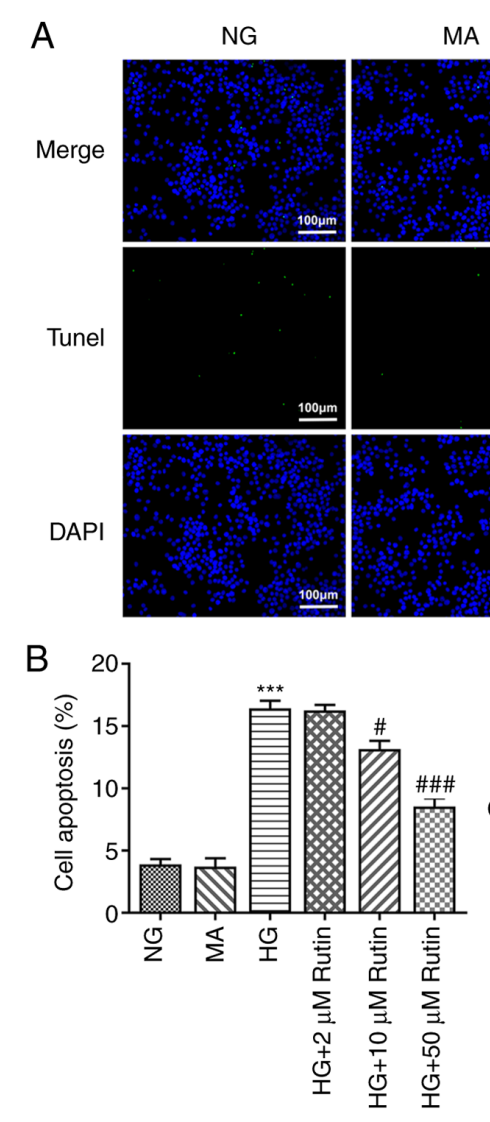

MA

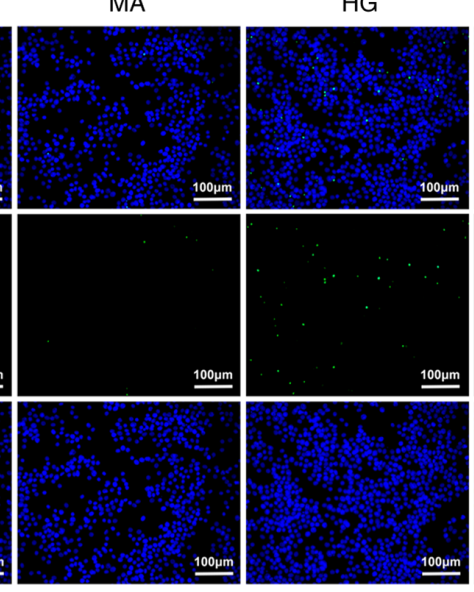

C

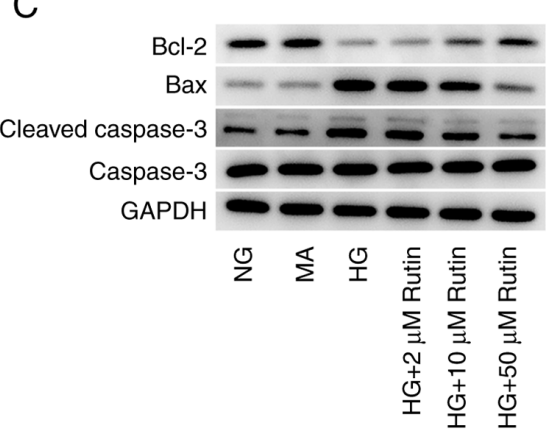

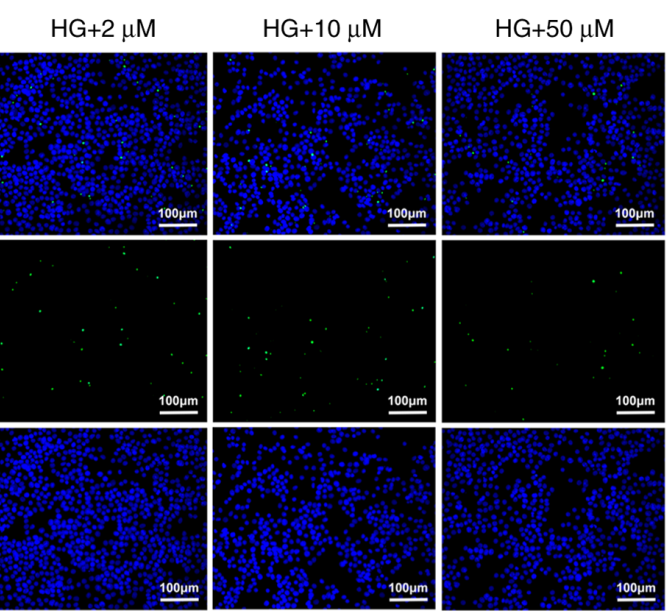
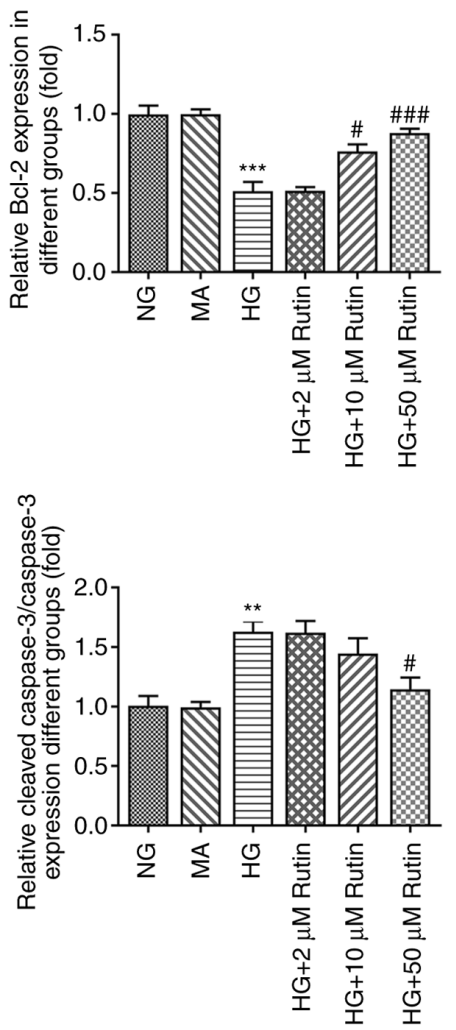

Figure 3. Rutin inhibits apoptosis of H9C2 cells induced by high glucose. (A) Tunel assay was used to analyze the apoptosis level of cells. (B) Quantitative analysis of the percentage of apoptotic cells. (C) Western blot analysis was used to determine the levels of apoptosis related proteins. HG, high glucose; NG, normal glucose; MA, mannitol. ${ }^{* *} \mathrm{P}<0.01,{ }^{* * * *} \mathrm{P}<0.001$ vs. MA. ${ }^{\#} \mathrm{P}<0.05,{ }^{\# \#} \mathrm{P}<0.001$ vs. HG. 

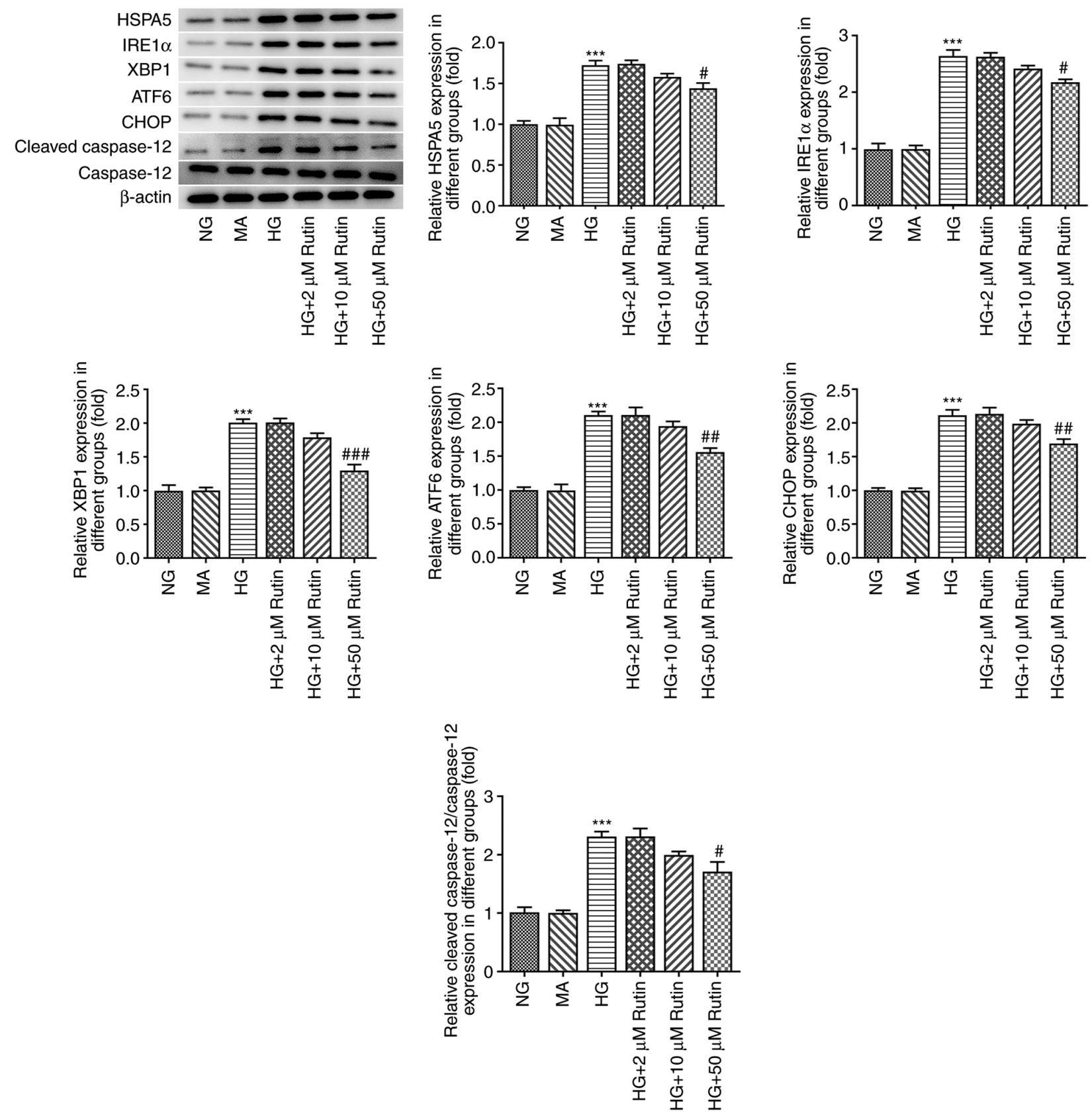

Figure 4. Rutin inhibits ERS in H9C2 cells treated with HG. Western blotting analysis was used to determine the expression levels of ERS related proteins. ERS, endoplasmic reticulum stress; HG, high glucose; NG, normal glucose; MA, mannitol; HSPA5, heat shock protein A5; IRE1 $\alpha$, insulin response element 1 $\alpha$; XBP1, X-box binding protein 1; CHOP, C/EBP-homologous protein; ATF6, activating transcription factor $6 .{ }^{* * *} \mathrm{P}<0.001$ vs. MA. ${ }^{\# P}<0.05,{ }^{\# \#} \mathrm{P}<0.01,{ }^{\# \# "} \mathrm{P}<0.001$ vs. HG.

\section{Results}

Rutin inhibits the apoptosis of $H 9 C 2$ cells stimulated by $H G$. The structure of rutin is presented in Fig. 1. Different concentrations of rutin $(2,10$ and $50 \mu \mathrm{M})$ were applied to $\mathrm{H} 9 \mathrm{C} 2$ cells and a CCK-8 assay was used to detect the activity of $\mathrm{H} 9 \mathrm{C} 2$ cells. Rutin had no significant effect on the viability of H9C2 cells (Fig. 2A). This indicated that the concentration of rutin used was not cytotoxic to $\mathrm{H} 9 \mathrm{C} 2$ cells. HG-stimulated $\mathrm{H} 9 \mathrm{C} 2$ cells were treated with different concentrations of rutin and the cells were sorted into the $\mathrm{NG}, \mathrm{MA}, \mathrm{HG}, \mathrm{HG}+2 \mu \mathrm{M}$ rutin, $\mathrm{HG}+10 \mu \mathrm{M}$ rutin and $\mathrm{HG}+50 \mu \mathrm{M}$ rutin groups. The results of the CCK-8 assay demonstrated that, compared with the MA group, cell viability was reduced in the HG group. Moreover, after administering increasing concentrations of rutin, cell viability was enhanced in a concentration-dependent manner (Fig. 2B).

An LDH kit was used to detect the effect of rutin on cytotoxicity induced by HG. The results demonstrated that cytotoxicity was significantly increased by HG in comparison with MA. After rutin was administered, the HG-induced cytotoxicity gradually decreased as the concentration of rutin increased (Fig. 2C).

Apoptosis was assessed using a TUNEL assay, and the results are presented in Fig. 3. Compared with the MA group, the apoptotic rate was significantly increased after HG incubation (Fig. 3A), accompanied by increased expression levels of 
A

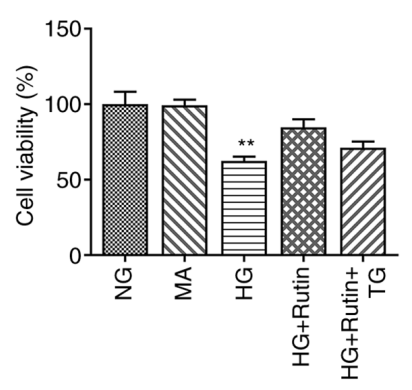

B

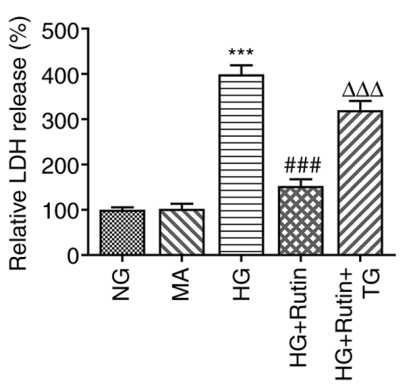

C

NG

MA
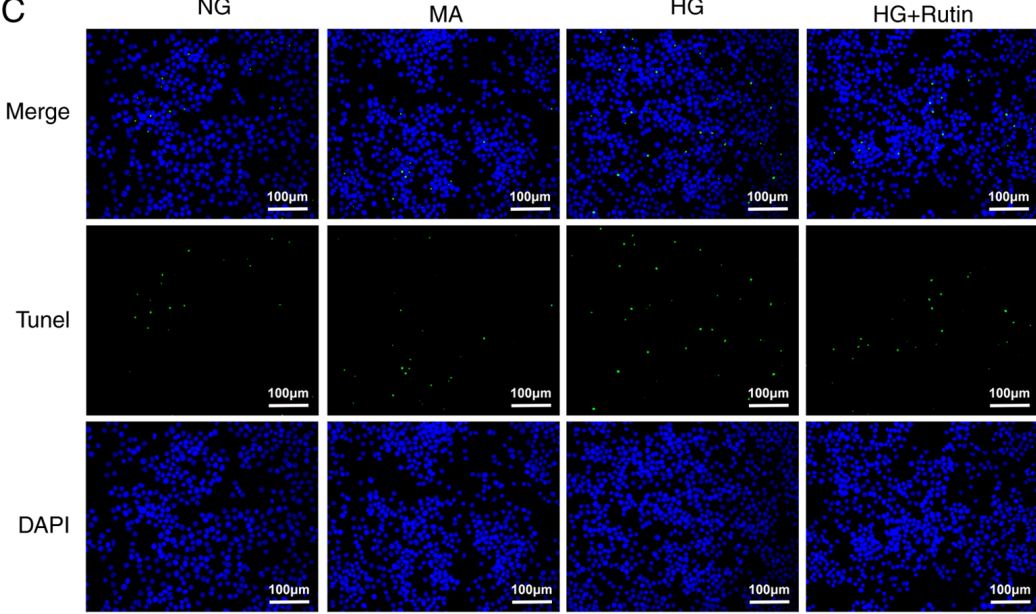

HG+Rutin+TG
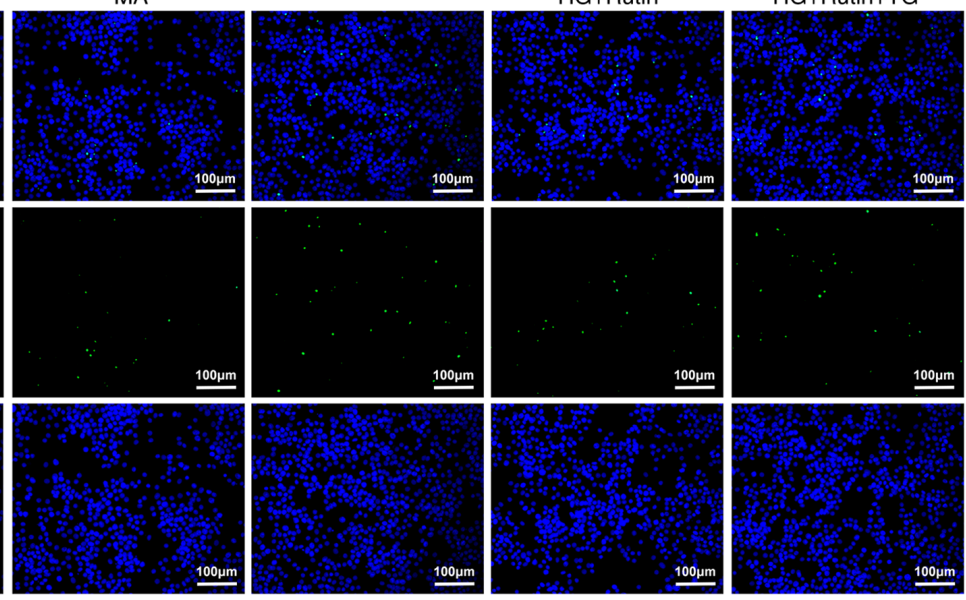

D

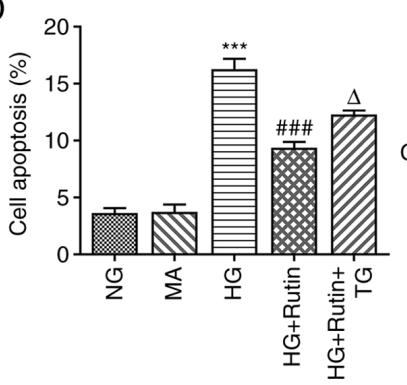

E
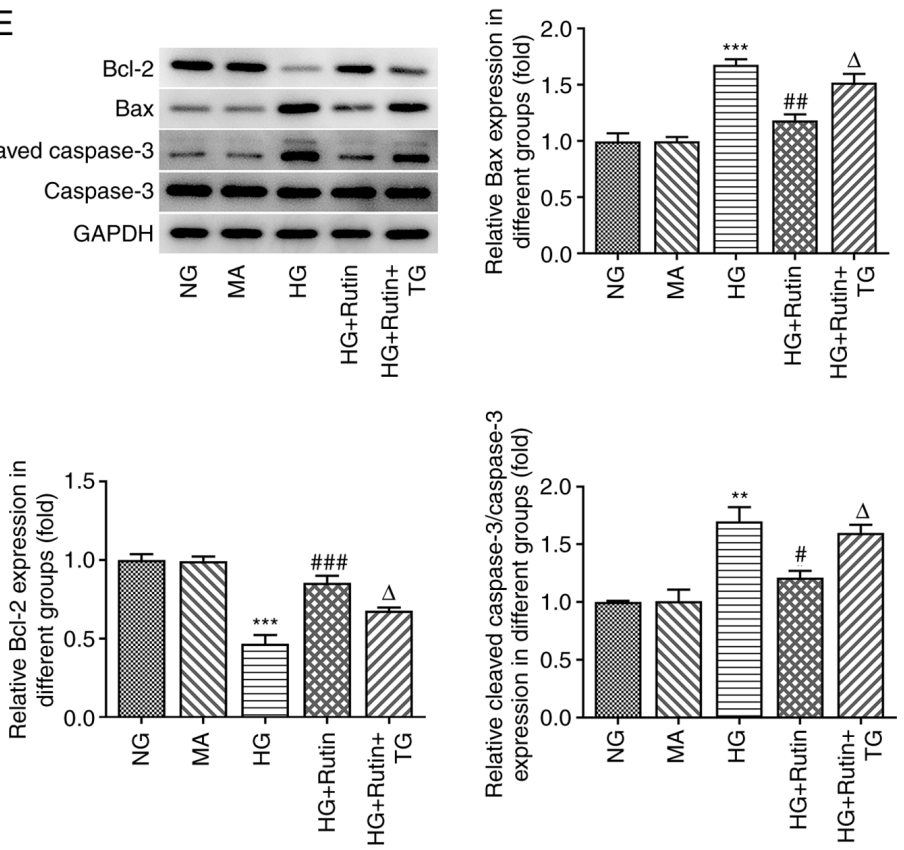

Figure 5. TG reverses the anti-apoptotic effect of rutin on H9C2 cells induced by high glucose. (A) Cell viability was determined by CCK-8. (B) LDH kit was used to determine cytotoxicity. (C) Tunel assay determined the apoptosis level of cells. (D) Quantitative analysis of the apoptosis level in cells. (E) Western blot analysis was used to determine the expression levels of apoptosis related proteins. TG, thapsigargin; CCK-8, cell counting kit-8; LDH, lactate dehydrogenase; $\mathrm{HG}$, high glucose; NG, normal glucose; MA, mannitol. ${ }^{* *} \mathrm{P}<0.01,{ }^{* * * *} \mathrm{P}<0.001$ vs. MA. ${ }^{\#} \mathrm{P}<0.05,{ }^{\# \#} \mathrm{P}<0.01,{ }^{\# \# \#} \mathrm{P}<0.001$ vs. HG. ${ }^{\Delta} \mathrm{P}<0.05,{ }^{\Delta \Delta \Delta} \mathrm{P}<0.001$ vs. HG $+\mathrm{Rutin}$.

Bax and cleaved caspase-3 and the reduced expression of Bcl-2 (Fig. 3B). Compared with the HG group, the apoptotic rate was significantly reduced in the $\mathrm{HG}+2 \mu \mathrm{M}$ rutin group, the $\mathrm{HG}+$ $10 \mu \mathrm{M}$ rutin group and the $\mathrm{HG}+50 \mu \mathrm{M}$ Rutin group, accompanied by decreased expression levels of Bax and cleaved caspase-3, and the increased expression of Bcl-2. These results indicated that Rutin may inhibit the apoptosis of H9C2 cells induced by HG.
Rutin inhibits ERS in HCc2 cells treated with HG. Western blotting was used to determine the expression levels of the proteins GRP78, IRE1 $\alpha$, XBP1, ATF6, CHOP, cleaved caspase 12 and caspase 12, which are associated with ERS-related pathways. It was revealed that, compared with MA treatment, expression levels of the ERS-related proteins GRP78, IRE1 $\alpha$, XBP1, ATF6, CHOP and cleaved caspase-12 were significantly increased in the HG treatment group, 

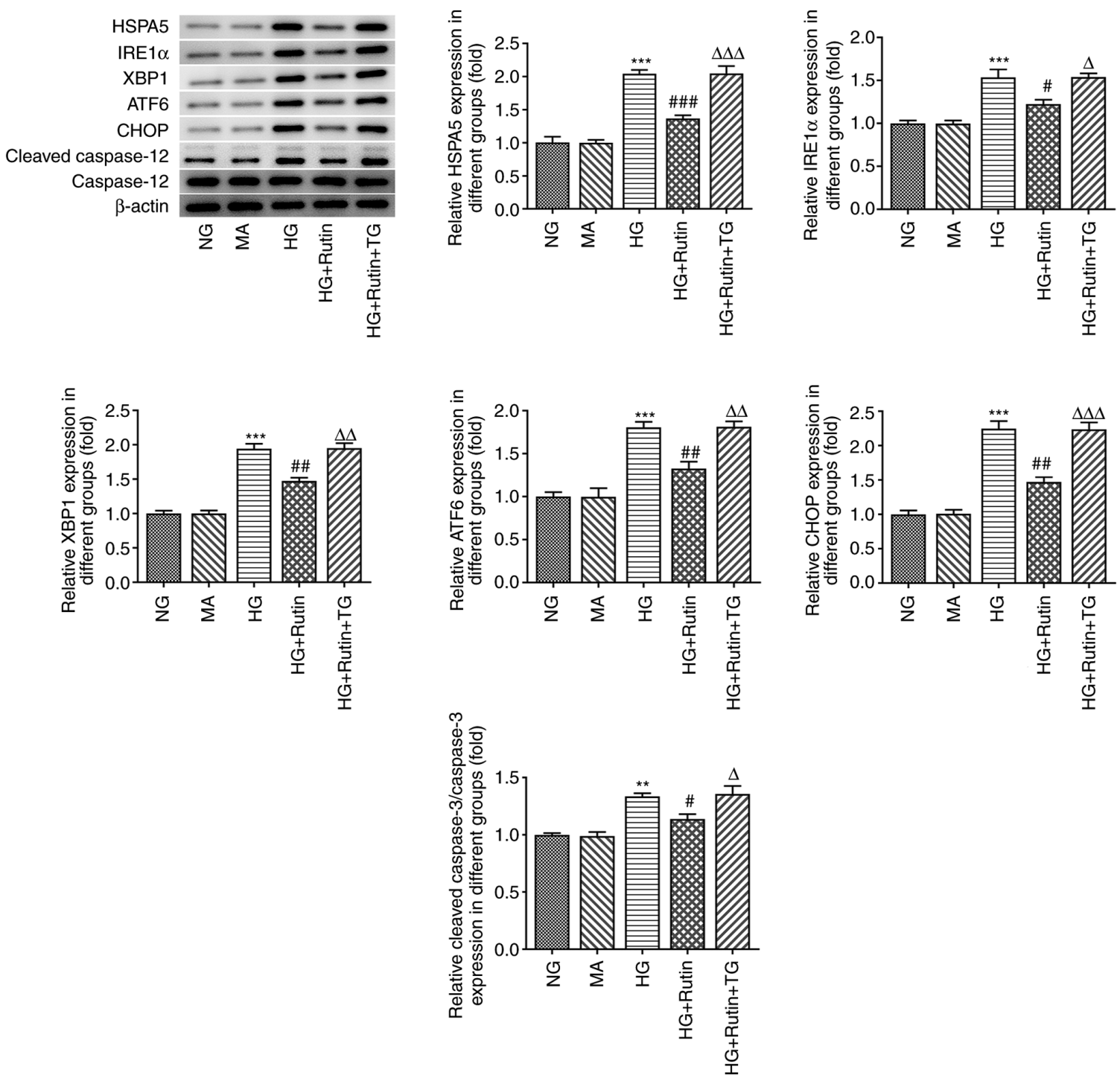

Figure 6. TG reverses the anti-ERS effect of rutin on $\mathrm{H} 9 \mathrm{C} 2$ cells treated with HG. Western blotting analysis was used to determine the expression levels of ERS related proteins. TG, thapsigargin; ERS, endoplasmic reticulum stress; HG, high glucose; NG, normal glucose; MA, mannitol; HSPA5, heat shock protein A5; IRE1 $\alpha$, insulin response element $1 \alpha$; XBP1, X-box binding protein 1; CHOP, C/EBP-homologous protein; ATF6, activating transcription factor 6 ** P<0.01, ${ }^{* * * *} \mathrm{P}<0.001$ vs. MA. ${ }^{\# \mathrm{P}}<0.05,{ }^{\# \#} \mathrm{P}<0.01,{ }^{\# \# \#} \mathrm{P}<0.001$ vs. HG. ${ }^{\Delta} \mathrm{P}<0.05,{ }^{\Delta \Delta} \mathrm{P}<0.01,{ }^{\Delta \Delta \Delta} \mathrm{P}<0.001$ vs. $\mathrm{HG}+$ Rutin.

indicating increased ERS levels. Compared with the HG group, the expression levels of ERS-related proteins in the $\mathrm{HG}+2 \mu \mathrm{M}$ rutin group and the $\mathrm{HG}+10 \mu \mathrm{M}$ rutin group were decreased, but this was not significant; however, the expression levels of ERS-related proteins in the $\mathrm{HG}+50 \mu \mathrm{M}$ rutin group were significantly decreased (Fig. 4). Therefore, $50 \mu \mathrm{M}$ rutin was selected for subsequent experiments. These results preliminarily indicated that rutin may inhibit the ERS of $\mathrm{H} 9 \mathrm{C} 2$ cells treated with $\mathrm{HG}$.

$T G$ reverses the anti-apoptotic effect of Rutin on $\mathrm{H} 9 \mathrm{C} 2$ cells induced by $H G$. To further verify the results, $2 \mu \mathrm{M}$ of the ERS activator TG was added to cells for $4 \mathrm{~h}$, and the cells were divided into the NG group, MA group, $\mathrm{HG}$ group, $\mathrm{HG}+$ rutin group and $\mathrm{HG}+$ rutin $+\mathrm{TG}$ group. It was found that, compared with the $\mathrm{HG}+$ rutin group, the viability of the $\mathrm{HG}+$ rutin + TG group was significantly decreased (Fig. 5A), while the cytotoxicity (Fig. 5B) and apoptosis (Fig. 5C and D) levels were significantly increased. These effects were accompanied by increased expression levels of Bax and cleaved caspase-3, and the decreased expression of Bcl-2 (Fig. 5E). These results demonstrated that TG reversed the anti-apoptotic effect of rutin on $\mathrm{H} 9 \mathrm{C} 2$ cells treated with $\mathrm{HG}$.

$T G$ reverses the anti-ERS effect of rutin on $H 9 C 2$ cells treated with $H G$. ERS-related proteins were also detected in the cells, as presented in Fig. 6. Compared with the HG + rutin group, GRP78, IRE1 $\alpha$, XBP1, ATF6, CHOP and cleaved caspase-12 expression levels were significantly increased in the HG + rutin + TG group, indicating that TG reversed the anti-ERS effect of Rutin in $\mathrm{H} 9 \mathrm{C} 2$ cells treated with HG.

\section{Discussion}

Diabetic cardiomyopathy is one of the main complications of diabetes and one of the largest causes of mortality in patients with diabetes (25). Moreover, its pathogenesis is complex and has not been fully defined (26). In recent years, studies have 
reported that excessive ERS lead to the apoptosis of cardiomyocytes (27-29). Thus, how to alleviate ERS-induced injury is a hot topic of research. The present study induced a model of myocardial damage in $\mathrm{H} 9 \mathrm{C} 2$ myoblasts using $\mathrm{HG}$. The results demonstrated that cell viability, was reduced while cytotoxicity, apoptosis and the ERS level were increased after HG treatment. These experimental results were consistent with those of Cao et al (24), indicating that the diabetic myocardial injury model was successfully induced.

In the present study $\mathrm{H} 9 \mathrm{C} 2$ myoblasts were incubated with $\mathrm{HG}$ to form a diabetic myocardial injury model. However, a limitation of this work is that the regulatory effect of rutin on diabetic myocardial injury in rats was not determined in vivo. In addition, though the present study explored the effect of rutin on HG-induced myocardial apoptosis and injury, inflammation, which plays an important role in the myocardial injury induced by high glucose (24) was not addressed. In future experiments, our research group will address these limitations.

A previous study revealed that rutin alleviated hypoxia/reoxygenation myocardial cell injury by upregulating sirtuin 1 expression (30). Rutin also has a protective effect against cardiotoxicity induced by pirobilin via the TGF- $\beta 1 /$ p38MAPK signaling pathway (31). In addition, rutin improves metabolic acidosis and fibrosis in rats with alloxan-induced diabetic nephropathy and cardiomyopathy (32). However, to the best of our knowledge, the role of rutin in HG-induced cardiomyocyte injury has not been previously reported. The present results indicated that rutin may inhibit the apoptosis and ERS response of HG-treated H9C2 cells and may therefore be useful in the treatment of diabetic cardiomyopathy.

GRP78 is an important substance involved in the folding of proteins in ERS. Moreover, its expression level increases significantly during ERS, and it can be used as a marker molecule for ERS (33). The endoplasmic reticulum and a steady state of cell function are vital to balance the proteome, and so, when cells are in a state of ERS, a series of regulatory mechanisms are rapidly activated to combat this stress state (34). Among them, the UPR is the major regulatory mechanism in response to ERS (35). The UPR controls the expression levels of endoplasmic reticulum-associated proteins via three protein receptors located in the endoplasmic reticulum (PERK, IRE1 $\alpha$ and ATF6) (36,37). In addition, activation of caspase 12 has been revealed to be mainly associated with ERS $(38,39)$. Therefore, the present study assessed ERS status by determining the expression levels of GRP78, IRE1 $\alpha$, XBP1, ATF6, CHOP, cleaved caspase 12 and caspase 12. The present study found that after HG administration, the expression levels of ERS-related proteins were significantly increased in comparison with controls. After the administration of rutin, the HG-induced expression levels of ERS-related proteins were significantly reduced, though the administration of TG could significantly reverse the inhibitory effect of rutin on HG-induced ERS in cardiomyocytes. Thus, the present study demonstrated that rutin could inhibit the ERS response to reduce $\mathrm{HG}$-induced myocardial cell injury.

In conclusion, rutin may alleviate cardiomyocyte injury induced by HG through inhibition of apoptosis and ERS. The present study provides a theoretical basis for the treatment of myocardial injury with rutin.

\section{Acknowledgements}

Not applicable.

\section{Funding}

No funding was received.

\section{Availability of data and materials}

The datasets used and/or analyzed during the current study are available from the corresponding author on reasonable request.

\section{Authors' contributions}

JW made substantial contributions to the conception and design of the study, and the acquisition of data. RW and JL made substantial contributions to analysis and interpretation of data. ZY confirm the authenticity of all the raw data. All authors read and approved the final manuscript.

\section{Ethics approval and consent to participate}

Not applicable.

\section{Patient consent for publication}

Not applicable.

\section{Competing interests}

The authors declare that they have no competing interests.

\section{References}

1. Lorenzo-Almoros A, Cepeda-Rodrigo JM and Lorenzo O: Diabetic cardiomyopathy. Rev Clin Esp, 2020 (In English, Spanish) (Epub ahead of print).

2. Xia L and Song M: Role of non-coding RNA in diabetic cardiomyopathy. Adv Exp Med Biol 1229: 181-195, 2020.

3. Tan Y, Zhang Z, Zheng C, Wintergerst KA, Keller BB and Cai L: Mechanisms of diabetic cardiomyopathy and potential therapeutic strategies: Preclinical and clinical evidence. Nat Rev Cardiol 17: 585-607, 2020.

4. Hosseinzadeh $\mathrm{H}$ and Nassiri-Asl M: Review of the protective effects of rutin on the metabolic function as an important dietary flavonoid. J Endocrinol Invest 37: 783-788, 2014.

5. Ganeshpurkar A and Saluja AK: The pharmacological potential of rutin. Saudi Pharm J 25: 149-164, 2017.

6. Dubey S, Ganeshpurkar A, Shrivastava A, Bansal D and Dubey N: Rutin exerts antiulcer effect by inhibiting the gastric proton pump. Indian J Pharmacol 45: 415-417, 2013.

7. Ruangsuriya J, Charumanee S, Jiranusornkul S, Sirisa-Ard P, Sirithunyalug B, Sirithunyalug J, Pattananandecha T and Saenjum C: Depletion of $\beta$-sitosterol and enrichment of quercetin and rutin in Cissus quadrangularis Linn fraction enhanced osteogenic but reduced osteoclastogenic marker expression. BMC Complement Med Ther 20: 105, 2020.

8. Manzoni AG, Passos DF, Leitemperger JW, Storck TR, Doleski PH, Jantsch MH, Loro VL and Leal DBR: Hyperlipidemia-induced lipotoxicity and immune activation in rats are prevented by curcumin and rutin. Int Immunopharmacol 81: 106217, 2020.

9. Nouri Z, Fakhri S, Nouri K, Wallace CE, Farzaei MH and Bishayee A: Targeting multiple signaling pathways in cancer: The rutin therapeutic approach. Cancers (Basel) 12: 2276, 2020 . 
10. Guimaraes JF, Muzio BP, Rosa CM, Nascimento AF, Sugizaki MM, Fernandes AA, Cicogna AC, Padovani CR, Okoshi MP and Okoshi K: Rutin administration attenuates myocardial dysfunction in diabetic rats. Cardiovasc Diabetol 14: 90, 2015.

11. Huang R, Shi Z, Chen L, Zhang Y, Li J and An Y: Rutin alleviates diabetic cardiomyopathy and improves cardiac function in diabetic ApoEknockout mice. Eur J Pharmacol 814: 151-160, 2017.

12. Sundaram RL, Sali VK and Vasanthi HR: Protective effect of rutin isolated from Spermococe hispida against cobalt chloride-induced hypoxic injury in $\mathrm{H} 9 \mathrm{c} 2$ cells by inhibiting oxidative stress and inducing apoptosis. Phytomedicine 51: 196-204, 2018

13. Jeong JJ, Ha YM, Jin YC, Lee EJ, Kim JS, Kim HJ, Seo HG, Lee JH, Kang SS, Kim YS and Chang KC: Rutin from Lonicera japonica inhibits myocardial ischemia/reperfusion-induced apoptosis in vivo and protects $\mathrm{H} 9 \mathrm{c} 2$ cells against hydrogen peroxide-mediated injury via ERK1/2 and PI3K/Akt signals in vitro. Food Chem Toxicol 47: 1569-1576, 2009.

14. Oakes SA: Endoplasmic reticulum stress signaling in cancer cells. Am J Pathol 190: 934-946, 2020.

15. Liu Q, Korner H, Wu H and Wei W: Endoplasmic reticulum stress in autoimmune diseases. Immunobiology 225: 151881, 2020.

16. Hetz $C$ and Saxena S: ER stress and the unfolded protein response in neurodegeneration. Nat Rev Neurol 13: 477-491, 2017.

17. Wang Y, Cao L and Liu X: Ghrelin alleviates endoplasmic reticulum stress and inflammation-mediated reproductive dysfunction induced by stress. J Assist Reprod Genet 36: 2357-2366, 2019.

18. Lima NCR, Melo TQ, Sakugawa AYS, Melo KP and Ferrari MFR Restoration of Rab1 levels prevents endoplasmic reticulum stress in hippocampal cells during protein aggregation triggered by rotenone. Neuroscience 419: 5-13, 2019.

19. Brenjian S, Moini A, Yamini N, Kashani L, Faridmojtahedi M, Bahramrezaie $\mathrm{M}$ and Amidi F: Resveratrol treatment in patients with polycystic ovary syndrome decreased pro-inflammatory and endoplasmic reticulum stress markers. Am J Reprod Immunol 83: e13186, 2020.

20. Suzuki R, Fujiwara Y, Saito M, Arakawa S, Shirakawa JI, Yamanaka M, Komohara Y, Marumo K and Nagai R: Intracellular accumulation of advanced glycation end products induces osteoblast apoptosis via endoplasmic reticulum stress. J Bone Miner Res 35: 1992-2003, 2020

21. Villalobos-Labra R, Subiabre M, Toledo F, Pardo F and Sobrevia L: Endoplasmic reticulum stress and development of insulin resistance in adipose, skeletal, liver, and foetoplacental tissue in diabesity. Mol Aspects Med 66: 49-61, 2019.

22. Rozpedek W, Pytel D, Mucha B, Leszczynska H, Diehl JA and Majsterek I: The Role of the PERK/eIF2 $\alpha / A T F 4 / C H O P$ signaling pathway in tumor progression during endoplasmic reticulum stress. Curr Mol Med 16: 533-544, 2016.

23. Su S, Li X, Li S, Ming P, Huang Y, Dong Y, Ding H, Feng S, Li J, Wang X, et al: Rutin protects against lipopolysaccharide-induced mastitis by inhibiting the activation of the NF- $\kappa B$ signaling pathway and attenuating endoplasmic reticulum stress. Inflammopharmacology 27: 77-88, 2019.

24. Cao R, Fang D, Wang J, Yu Y, Ye H, Kang P, Li Z, Wang H and Gao Q: ALDH2 overexpression alleviates high glucose-induced cardiotoxicity by inhibiting NLRP3 inflammasome activation. J Diabetes Res 2019: 4857921, 2019.
25. Bugger $H$ and Abel ED: Molecular mechanisms of diabetic cardiomyopathy. Diabetologia 57: 660-671, 2014.

26. Tadic M, Cuspidi C, Calicchio F, Grassi G and Mancia G: Diabetic cardiomyopathy: How can cardiac magnetic resonance help? Acta Diabetol 57: 1027-1034, 2020.

27. Zeng Z, Huang N, Zhang Y, Wang Y, Su Y, Zhang H and An Y: CTCF inhibits endoplasmic reticulum stress and apoptosis in cardiomyocytes by upregulating RYR2 via inhibiting S100A1. Life Sci 242: 117158, 2020.

28. Li L, Peng X, Guo L, Zhao Y and Cheng Q: Sepsis causes heart injury through endoplasmic reticulum stress-mediated apoptosis signaling pathway. Int J Clin Exp Pathol 13: 964-971, 2020.

29. Wilson AJ, Gill EK, Abudalo RA, Edgar KS, Watson CJ and Grieve DJ: Reactive oxygen species signalling in the diabetic heart: Emerging prospect for therapeutic targeting. Heart 104: 293-299, 2018.

30. Yang H, Wang C, Zhang L, Lv J and Ni H: Rutin alleviates hypoxia/reoxygenation-induced injury in myocardial cells by up-regulating SIRT1 expression. Chem Biol Interact 297: 44-49, 2019.

31. Wang Y, Zhang Y, Sun B, Tong Q and Ren L: Rutin protects against pirarubicin-induced cardiotoxicity through TGF- $31-$ p38 MAPK signaling pathway. Evid Based Complement Alternat Med 2017: 1759385, 2017.

32. Ganesan D, Albert A, Paul E, Ananthapadmanabhan K, Andiappan R and Sadasivam SG: Rutin ameliorates metabolic acidosis and fibrosis in alloxan induced diabetic nephropathy and cardiomyopathy in experimental rats. Mol Cell Biochem 471: 41-50, 2020.

33. Ardic S, Gumrukcu A, Gonenc Cekic O, Erdem M, Reis Kose GD, Demir S, Kose B, Yulug E, Mentese A and Turedi S: The value of endoplasmic reticulum stress markers (GRP78 and CHOP) in the diagnosis of acute mesenteric ischemia. Am J Emerg Med 37: 596-602, 2019.

34. Oakes SA and Papa FR: The role of endoplasmic reticulum stress in human pathology. Annu Rev Pathol 10: 173-194, 2015.

35. Hetz $\mathrm{C}$ and Papa FR: The unfolded protein response and cell fate control. Mol Cell 69: 169-181, 2018.

36. Hetz C: The unfolded protein response: Controlling cell fate decisions under ER stress and beyond. Nat Rev Mol Cell Biol 13: 89-102, 2012

37. Gong J, Wang XZ, Wang T, Chen JJ, Xie XY, Hu H, Yu F, Liu HL, Jiang XY and Fan HD: Molecular signal networks and regulating mechanisms of the unfolded protein response. J Zhejiang Univ Sci B 18: 1-14, 2017.

38. Wu Z, Wang H, Fang S and Xu C: Roles of endoplasmic reticulum stress and autophagy on $\mathrm{H} 2 \mathrm{O} 2$-induced oxidative stress injury in HepG2 cells. Mol Med Rep 18: 4163-4174, 2018.

39. Zuo S, Kong D, Wang C, Liu J, Wang Y, Wan Q, Yan S, Zhang J, Tang J, Zhang Q, et al: CRTH2 promotes endoplasmic reticulum stress-induced cardiomyocyte apoptosis through m-calpain. EMBO Mol Med 10: e8237, 2018.

This work is licensed under a Creative Commons Attribution-NonCommercial-NoDerivatives 4.0 International (CC BY-NC-ND 4.0) License. 